\title{
Is Plastic Bag Ordinance Effective? Evidence from Carbon Emissions in China
}

\author{
Xiufeng Xing ${ }^{1} \&$ Hongyu Liu ${ }^{1}$ \\ ${ }^{1}$ Business School, Qingdao University of Technology, Qingdao 266520, China \\ Correspondence: Xiufeng Xing, Business School, Qingdao University of Technology, Qingdao 266520, China. \\ E-mail: xxfqd@126.com
}

Received: March 5, 2018

Accepted: March 28, $2018 \quad$ Online Published: May 30, 2018

doi:10.5539/jsd.v11n3p158

URL: https://doi.org/10.5539/jsd.v11n3p158

\begin{abstract}
China has enacted the ordinance of plastic shopping bags since June 1 of 2008, which stipulates the bag thickness should be greater than or equal to 25 micrometers and consumers should pay for each bag they consume. However, the overall effect of the ordinance is lower-than-expected. This paper qualifies the carbon emissions associated with plastic shopping bag consumption in a fifteen year time series. The results indicate that, except for 2008, carbon emissions are on a continuous increase during this period. With respect to carbon emissions in 2008, there does appear a local minimum. Specifically, the carbon emissions relating to plastic bags in 2008 dropped $0.87 \%$ when compared with the emissions of 2007. This is not to suggest that the ordinance is effective in the long term, just that there is a slight carbon emission reduction in 2008. The transitory reduction of carbon emissions should be more attributed to the impact of Beijing Olympic Games than the effectiveness of the ordinance in hindsight. From 2009 on, the amount of carbon dioxide emissions generated by plastic shopping bags grows by $0.7-0.8 \%$ annually. Also, a two-child policy has taken into effect since 2011 which results in the net increase rate of entire population by $0.05 \%$ annually. When taken Beijing 2008 Olympic Games as well as the two-child population policy effect into consideration, it thus implies that the plastic bag ordinance may not be much effective to curb the bag usage in the long run. The theoretical and practical implications of the findings are discussed.
\end{abstract}

Keywords: plastic bag ordinance, plastic shopping bags, polluter (user) pays principle, carbon dioxide emissions, Beijing 2008 Olympic Games, two-child policy, China

\section{Introduction}

Given the pollution of plastic shopping bags, many countries and cities have taken actions to reduce future harm caused by them. China joined the list of countries to combat with plastic bags by prohibiting the production, sale and use of plastic bags $25 \mu$ (micrometers) thick or thinner nationwide. On June 1 of 2008, China enacted ordinance as well as a fee to consumers to curb the consumption of plastic bags. Before the ordinance, in order to win over public opinion in favor of reducing plastic shopping bag consumption nationwide, advertising campaign like providing reusable cloth bags to shoppers when shopping was conducted approximately half year in advance. Currently there are three types of plastic shopping bags in use. The unit price for the smallest size, medium size and the largest size is 0.1 yuan (0.014 USD), 0.2 yuan ( 0.029 USD) and 0.3 yuan ( 0.043 USD) respectively. In particular, retailers are not allowed to provide free substandard plastic bags to shoppers, and bags should be paid for use. According to the regulation, manufacturers are forced to produce standard plastic bags, retailers have to supply brand-new bags and shoppers should pay for every bag they use, just as the polluter (user) pays principle suggests. The ordinance should work well if all the stakeholders strictly abide by it. However, no significant results have been achieved in the past nine years. In effect, the ordinance may be referred to as a failure in terms of its poor performance so far. Although in the short period, due to Beijing 2008 Olympic Games, carbon dioxide emissions in cities like Beijing and Tianjin do outperform other cities and show a temporary reduction trend. After Olympic year, however, carbon emissions in all the 31 provinces in Chinese mainland rebounded, which revealed the overall effect of the ordinance on plastic bags was no better than a failure. In addition, based on our observation, at least $40 \%$ of open markets and wet markets still provide shoppers with free substandard plastic bags. Since the actual performance of regulation is lower-than-expected, it is of our interest to analyze this environmental policy by focusing on the carbon emissions in particular. 
A number of viewpoints have been presented in the literature to explore the effects of ban on plastic bags. Our comments will be brief and references to the existing literature will be less exhaustive, we only focus on those relative to this issue. First, with respect to the regulation on plastic bags in developing countries, Bangladesh was the first country to regulate bags in 2002 (Clapp et al., 2009). China's Taiwan is the next to impose heavy fines on those who distribute free bags. Estimation shows that the ban has positive environmental effect and has curbed bag usage by approximate 69\% (Laughlin 2004). South Africa has introduced a ban and taxation since late 2002. Besides the minimum thickness of $24 \mu$, a tax of 0.013 USD was added simultaneously (Hasson et al., 2007). In some sense, the ban is successful in terms of its minimum negative impact on plastic industry. Chinese mainland enacted an ordinance on plastic bags on June 1 of 2008, which was similar to that of South Africa. Saidan et al. (2017) highlight the levy on the plastic bags can reduce as much as $70 \%$ of the consumption In Jordan. However, with respect to China, the implementation of the ordinance was ineffective in the long term despite the fact that supermarkets had reduced the bags consumption by two-thirds (Zhu 2011) and $49 \%$ (He 2010). Additionally, the regulation showed only a short term or temporary decrease in two sample cities which could not represent the whole picture (He 2010). With time passing, Mortimer (2017) argues that bag consumption has rebounded in Ireland since 2007. It seems that there lacks a long term reduction effect either in Ireland or in China. Second, with regard to the situations in industrialized countries, Republic of Ireland which introduced the tax on plastic bags, the coined "plastax", in March of 2002 is a good case in point. Ireland achieves grand success in terms of its significant $90-95 \%$ bag usage reduction (Alexis 2017), but subsequent performance of bag reduction seems to have somewhat rebound effect since shoppers art conditioned to the charge (Mortimer 2017). Italy and France have introduced the bags ordinance in 2012 and January of 2017 respectively. In the City of Toronto, Rivers et al., (2017) find that the levy increased the use of reusable shopping bags by 3.4 percentage points which suggests crucial limitations for levy policy more generally since even people with lower socio-economic status have not been affected by this behavioural prompt. When it comes to the USA, San Francisco enacted a plastic bag ordinance in 2007. Moreover, a tax was imposed on most substitute goods except reusable bags. In general, it is local governments that are responsible for the plastic bags management (Wagner 2017). Last but not least, consumer behavior related to plastic bag consumption has also been widely investigated. Researchers mainly focus on topics including the effect of plastic bag tax on consumer behavior, and consumer attitudes and behavior on the use of plastic and cloth bags in various cities across the globe (Martinho et al., 2017; Jakovcevic et al., 2014; Ar1 et. al., 2017). However, to comment on the consumer behavior is well beyond the scope of this paper.

Although extensive research has been conducted on several aspects of plastic shopping bags, the literature regarding estimation of carbon dioxide emission associated with bag consumption is limited. To the best of our knowledge, Wang et al., $(2014,2016)$ have done similar research: they studied hidden carbon emissions in China Given the present state of the art of the carbon emissions relating to plastic shopping bags, they have rarely been researched into due to the limit of data availabilities. By focusing on the consumption of plastic bags before and after the implementation of the ordinance, specifically the after-ban-use of bags, this paper makes a small contribution to the estimate of carbon dioxide emissions associated with the plastic bag consumption.

The aim of this paper is to contribute to the better understanding of what makes regulation on plastic bags ineffective and how to make the ordinance work better in the future. The paper focuses on these issues by relying on data from China yearbook of statistics both before and after the implementation of the regulation. The ordinance turns out to be a failure in terms of its lower-than-expected effect. Nearly a decade has passed, still quite a number of producers are manufacturing substandard plastic bags and retailers are providing shoppers with this type of free bags. It is also of interest to investigate the reasons underlying the failure of the ban. The resulting information tends to help policy-makers acquire the long term plastic bag reduction and carbon dioxide emissions in future.

The remainder of the paper proceeds as follows: Section 2 discusses the methodology used and Section 3 describes the data. The results are reported in Section 4 and Section 5 concludes the paper.

\section{Methods}

To examine the effectiveness of the ban on plastic bags by estimating the carbon emissions associated with plastic bags, the paper analyzes the factors which influence plastic bags: population and unit price and quality of bag consumption. To be more concrete, the first factor focuses on the impact of population upon plastic bag consumption. Besides, we also take the impact of two-child policy which has been implementing since 2011 into consideration. According to our computation, the entire population has increased annually by $0.67 \%$ since 2011 which is a bit faster when compared with that of pre- 2011 which was $0.62 \%$, viz, the net increase rate of entire population is $0.05 \%$. The second factor concerns the unit price regarding bag use. In addition, the paper tries to 
explore other factor like the impact of Beijing 2008 Olympic Games. The paper focuses on these issues by relying on national and provincial-level data both before and after the implementation of the ordinance.

When analyzing the effect of the plastic bag ordinance in China, the paper attempts to construct an emission function to estimate the annual carbon dioxide emissions associated with the use of plastic shopping bags. The dependent variable $\mathrm{Y}$ in the function is the aggregate carbon emission (CE) per year, for the ease of exposition, here we employ $\mathrm{CE}$ instead of $\mathrm{Y}$, whereas the independent variable vector $X$ has several components, viz., $X=$ $\left(X_{p o p u}, X p, X q, X e\right)$. The first variable $X_{p o p u}$ denotes the national or provincial-level of population, the actual annual data comes from China yearbook of statistics in 2002-2016; $X p$ is the "unit price of various types of plastic bags"; $X q$ denotes the number of annual bag consumption of shoppers. If the unit price is equal to zero which means the bag is free of charge, it implies somewhat failure of the ban; if the unit price of each bag is nonzero, the ban should be theoretically effective. However, in empirical analysis, it is otherwise: that is, the fee fails to curb the plastic bag use. Xe denotes carbon dioxide emissions of plastic bags per kilogram which is constant given the existing technology.

The aforementioned independent variables will affect the carbon emissions dissimilarly. Here, the paper assumes the emission function is a type of production function which is concave upward; the variables of population and plastic bag use are the input. The paper sets up a simple carbon emission function which is expressed as:

$$
C E=\sum_{i=1}^{31} X_{\text {popu }}^{i} X_{q} X_{e}, \text { for } i=1,2, \ldots, 31 ; X q=f(X p) \geq 0, X p=0.1,0.2,0.3
$$

Where $C E$ is China's annual aggregate carbon dioxide emissions generated by plastic shopping bag usage; $X_{\text {popu }}{ }^{i}$ stands for the population of province $i$, there are 31 provinces, municipals and autonomous regions in Chinese mainland; $X q$ is the quantity of plastic bags used per person per year which is the demand function of $X_{p}$, viz., $X q$ $=\mathrm{f}(X p)$, currently, there are three types of unit price of plastic bags; and $X_{e}$ is the carbon emission of per kilogram plastic bags, it is constant given the existing technology, the value of $X_{e}$ is obtained from database of carbon emission in China.

Other countries' experiences show that whether or not the ordinance can succeed in reducing plastic bag use depends heavily on the effectiveness of regulation and the price level and the acceptance from the main stakeholders: producers, retailers as well as shoppers. The bag consumption is expected to decrease due to the price charged because, by definition, the typical demand function suggests that if price of good goes up, then the good consumption will go down, and vice versa.

The important point in this model is that carbon emission reduction is impossible unless (1) entire population growth is lowered or remains stable, or (2) the price instrument is in place such that the demand of plastic bags is slightly decreased or kept relatively stable. Neither of these possibilities seems very realistic since Chinese population is on a continuous rise in recent years; also, there is no national authority with the power as well as incentives to strictly enforce the plastic bag regulation.

Based upon our estimation, given the options between free substandard plastic bags and fee-charging bags, at least 80 percent shoppers prefer the former. There are no difference between the free plastic bags and fee-charging ones in terms of the amount of $\mathrm{CO}_{2}$ emission per kilogram.

The paper assumes that the data of some variables regarding plastic bag use could differ before and after the ordinance implementation. Similarly, the values of carbon dioxide emissions should vary accordingly. For instance, the unit price of bags can affect the amount of bag usage: before the enforcement of the ordinance, i.e., before June 1, 2008, shoppers may consume more bags since it is free; while after that time, presumably they may reduce bag use, especially the paid-for plastic bags. Alternatively, the shoppers can increase the use of free bags if the supervision of the ordinance is less strictly performed. As a consequence, the total amount of plastic bag consumption may remain the same or even increase to some extent.

\section{Data}

\subsection{Bag Consumption and Carbon Emissions before the Ordinance}

In order to estimate the carbon dioxide emissions regarding the bag consumption, we need to determine the variable of $X_{q}$, that is, the annual usage of plastic shopping bags. With regard to the total use of plastic bags, we tentatively argue that 521 plastic shopping bags had been consumed before June 1of 2008, because based on our individual-related data, each consumer gets at most 4 standard plastic bags per week per person from supermarkets. Meanwhile, at least 6 substandard plastic bags per person are obtained from open markets or/and wet markets. Thus, the summation of bags is about 521 per person per year. According to the survey, 21plastic 
bags were consumed per week per person on average (He, 2010). That is, approximately 1095 plastic bags were used annually prior to the implementation of the ordinance. By contrast, on average, 500 plastic bags are consumed per person per year in Jordan (Saidan et al., 2017) and 330 bags per person annually in Ireland respectively (Convery et al., 2007).

Given the amount of bag consumption between 521 and 1095, either one is much higher than that of Ireland and Jordan. Intuitively, the above figures overestimate the entire use of plastic bags in Chinese mainland pre-2008. For the sake of simplicity, we assume the quantity of plastic bags is 365 instead of 521 or 1095 per person per year to compute the carbon emissions before the ordinance, and 360 after the ordinance.

\subsection{Estimation of Carbon Emissions Associated with After-Ban-Use of Bags}

If plastic bags are recyclable and biodegradable, i.e., each can be used at least twice before littering, then after a certain period the littered bags can biodegrade and do less harm to the environment. However, there are quite a number of Chinese retailers at open and /or wet markets and rural fairs do not provide standard bags to shoppers, instead, as mentioned before, they offer free plastic bags which are less than $25 \mu$ to attract consumers. In this scenario, the actual usage of plastic shopping bags may not drop; or rather, they may augment in terms of the aggregate consumption of bags. Thus, the actual effect of the ordinance is lower-than-expected.

Essentially, the paper hypothesizes that the after-ban-use of plastic bags is only a slight decrease, compared to bag use before the ban. Here, suppose the amount of bags used before the ordinance equals 365, while the amount after the ordinance equals 360. This hypothesis justifies the reduction in after-ban-use of plastic bags is less, if any. Alternatively, the total amount of carbon dioxide emissions may even increase since free substandard plastic bags are still widely used in open markets and wet markets in lieu of our observation.

\section{Results and Discussion}

To verify the above assumption that the overall picture of carbon emissions may increase rather than decrease, we employ our theoretical model to calculate the carbon emissions. The computation result suggests that except for 2008, beginning with 2009, the amount of carbon emissions associated with plastic bag consumption increases by $0.7-0.8 \%$ annually. Figure 1 reports the final result of aggregate carbon emissions at national level in 2001-2015. Since Figure 1 has already displayed the characteristics of carbon emissions before and after 2008, to make our analysis simpler, in Figure 2 and 3, we only focus on the data in 2007-2015. Figure 2 reports the results of aggregate carbon emissions at provincial level. Figure 3 also presents the estimation of yearly carbon emissions across different provinces. The starting point of our analysis is from (Figure 1).

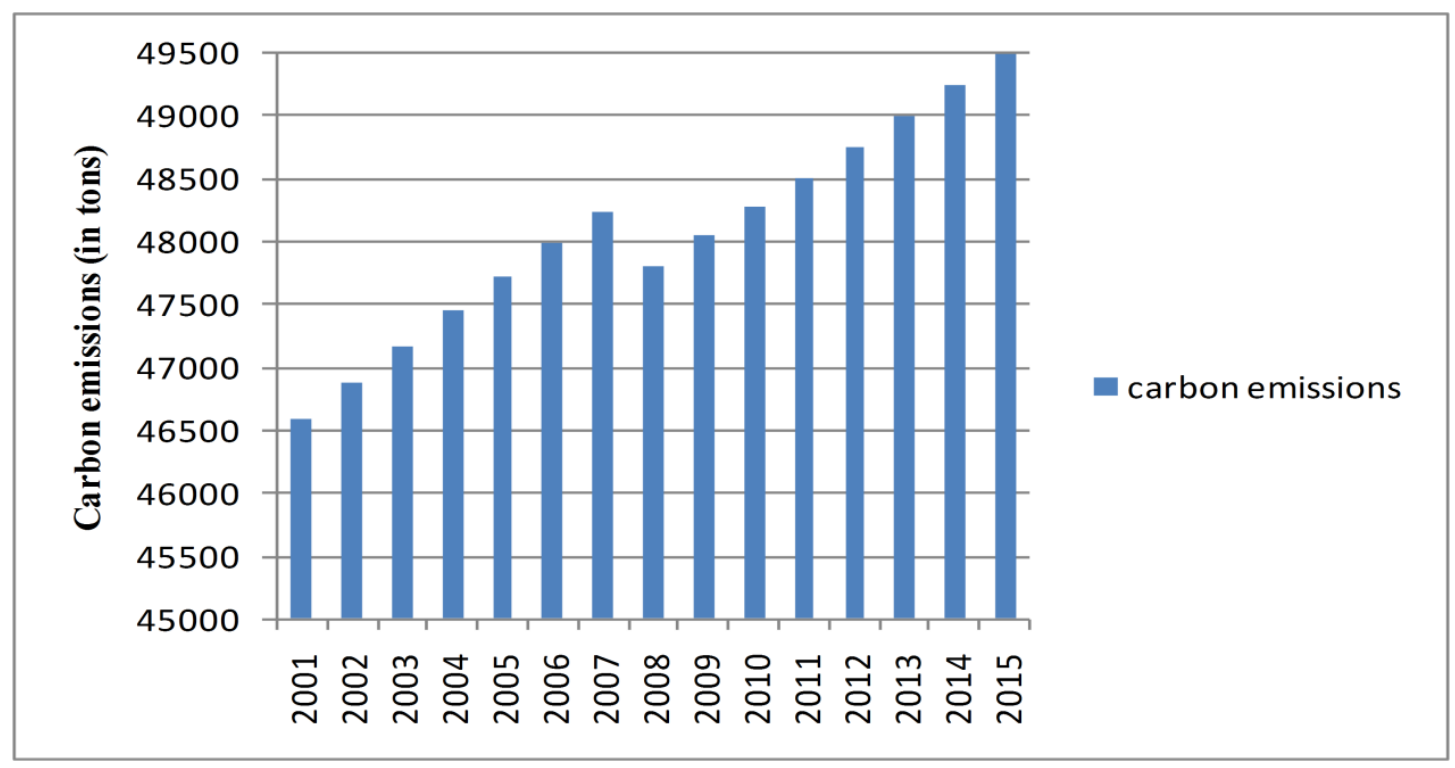

Figure 1. Aggregate carbon emissions at national level

Figure 1 shows a fifteen year time series of carbon emissions regarding plastic bag consumption in Chinese mainland. Notice here we use the entire national population which is the summation over the population of 31 provinces, municipals and autonomous regions to calculate carbon emissions. Specially, it illustrates that before 2007, the carbon emissions were increasing year by year. In particular, an emission peak with the value of 
48227.085 tons was appeared in 2007. In the following year, i.e., in 2008, however, the value was reduced to 47808.72 tons, and then from 2009 the emissions begin to increase. Thus, 47808.72 tons was a local minimum in 2008-2015.

It seems that the regulation only has a slightly short impact on the bag reduction as well as carbon emissions in 2008. It is worth noting that the price of plastic bag has little, if any, effect on consumer bag consumption in 2007 , in that bags were obtained completely free then. Although the theoretical value of bag usage in 2008 might be 362 which is $365^{*} 5 / 12+360 * 7 / 12$, given the ex-ante advertising campaign, it is possible that the actual number of bag use is lower than 362. For simplicity, we let the overall bag consumption be 360 in 2008. In this case, the quantity of carbon emissions was 47808.72 tons at the end of 2008 which was approximately $0.87 \%$ lower when compared with the carbon emissions of 48227.085 tons in 2007. This is not to suggest that the ordinance is effective in the long run, just that there exists a slight carbon emission reduction in 2008. If we take a look at the figures after 2008, then an increase trend seems to be significant. To be concrete, from 2009 on, the annual amount of aggregate carbon emissions associated with plastic bags shows a steady increase. Thus, coupled with the impacts of Beijing 2008 Olympic Games and the two-child policy, Figure 1 is twofold: only a short-term decrease effect of the ordinance on plastic shopping bags in Chinese mainland appeared in 2008. Nevertheless, it lacks a long run decrease effect; the latter can be further justified by both Figure 2 and Figure 3 below.

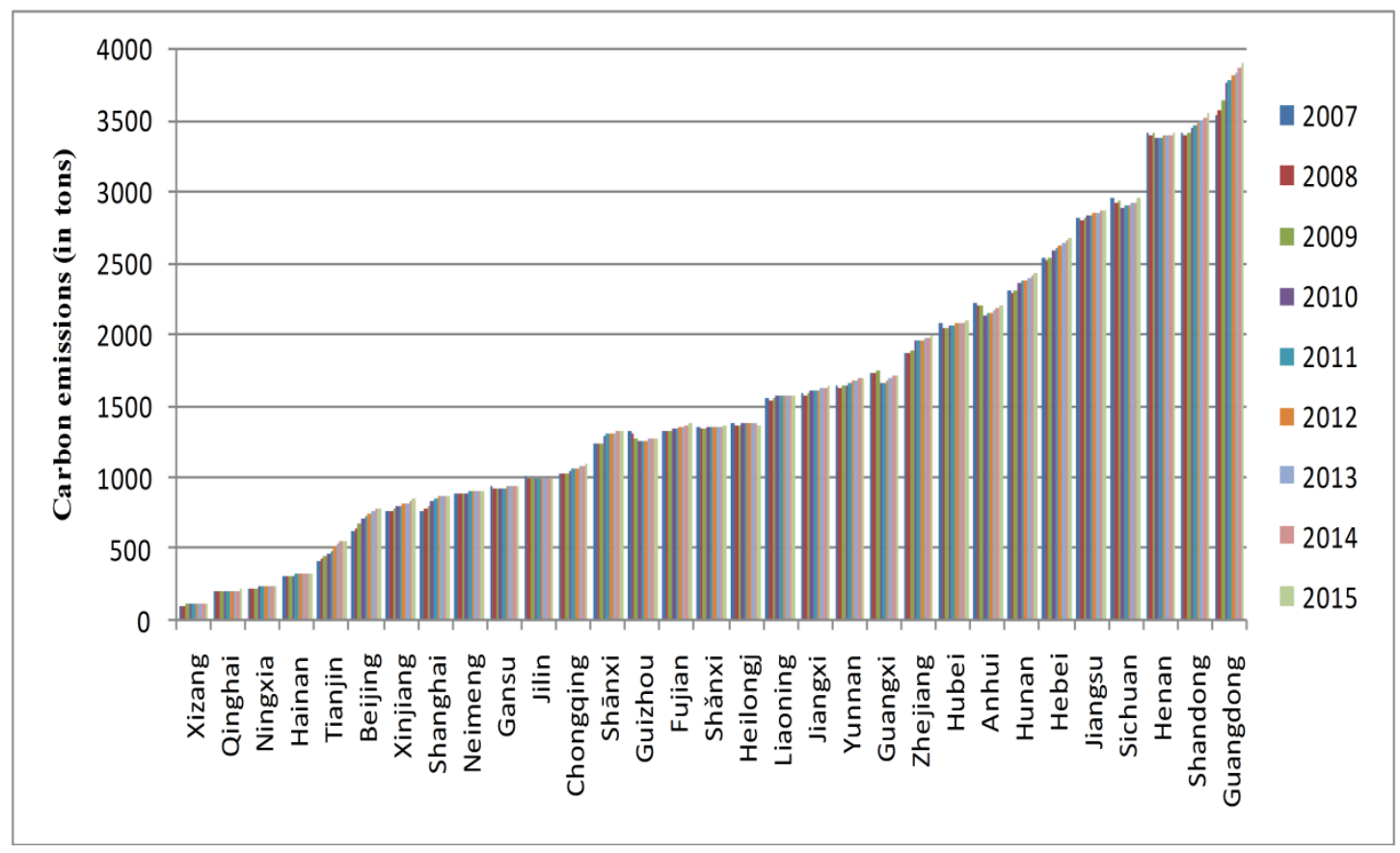

Figure 1. Aggregate carbon emissions at provincial level

From (figure 2), we can identify that in terms of the amount of carbon emissions before and after the 2008 ordinance, except for several provinces such as Xizang, Qinghai and Heilongjiang which show a tiny increase trend, the remainders are on a continuous increase. 


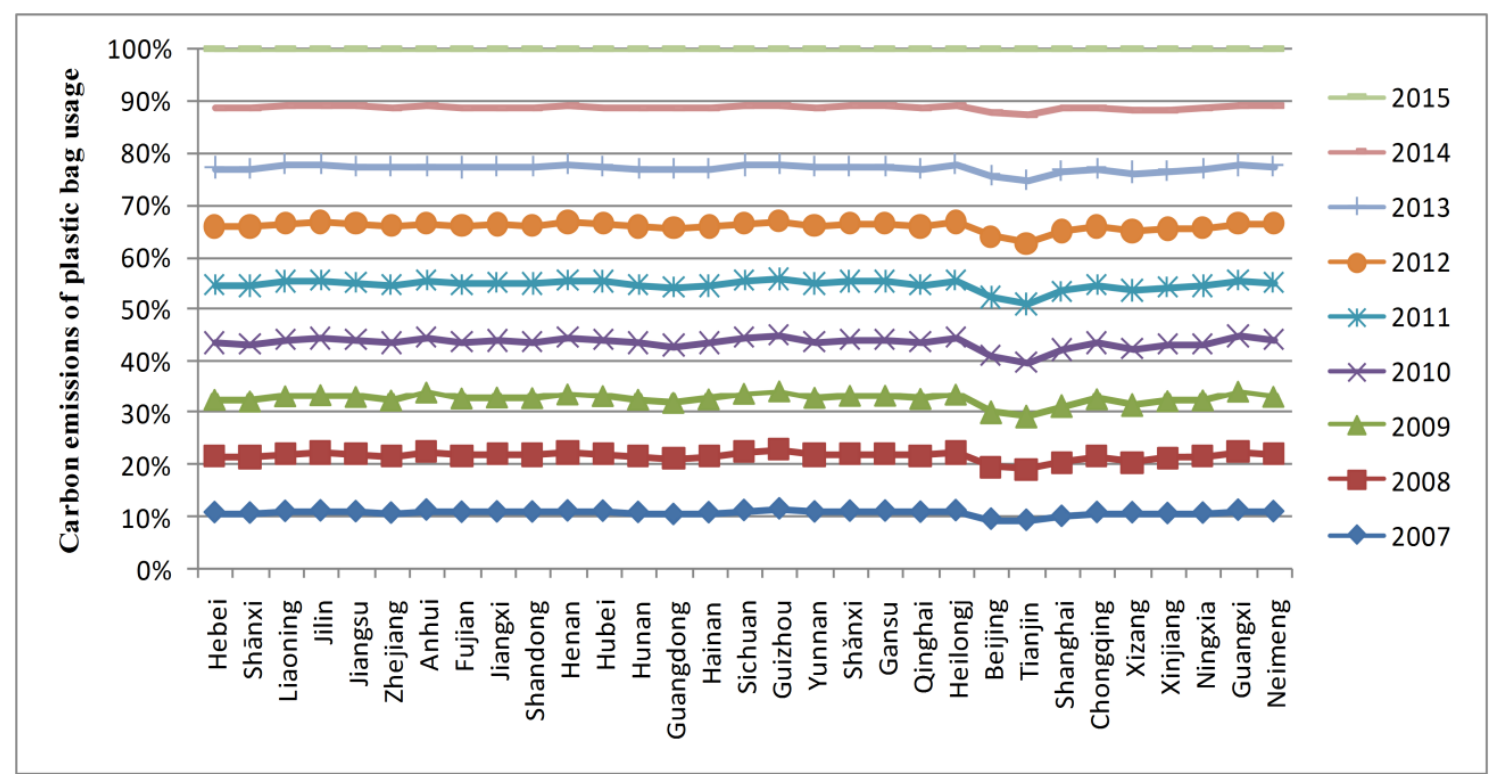

Figure 2. The estimation of yearly carbon emissions across different provinces

Figure3 illustrates that, as a whole, annual carbon emissions in almost all provinces are growing at different rate since 2008. Nevertheless, Beijing and Tianjin illustrate a slightly low increase rate in carbon emissions, particularly in 2008. Take the year of 2008 as an example, the main driving force for the reduction of plastic bags and carbon emissions thereby may attribute to the Beijing 2008 Olympic Games. Under this circumstance, both Beijing and Tianjin, made an obvious decrease in carbon emission that year. Note here Tianjin, which is adjacent to Beijing, is one of four municipal cities and also one of the six Olympic co-host cities which held football match. The other five co-host cities are: Hong Kong SAR, Qinhuangdao, Shanghai, Shenyang and Qingdao. When compared with 2007, the reduction rates in 2008, i.e., the Olympic year, were $4.22 \%$ and $4.03 \%$ for Beijing and Tianjin, respectively. It is noteworthy that during 2008, there was a small baby boom in China, especially for Beijing, Qingdao and other Olympic co-host cities. Thus, it is the push of Beijing Olympic games rather than the ban or/and the price instrument or/and population factor that contribute to the reduction in carbon emissions. For the remaining 29 provinces, municipals and autonomous regions, no such decrease trend appeared, no matter before or/and after the Olympic year. Also, due to the implementation of new two-child policy, population in China has been on an obvious increasing ever since 2011. It is the same with the carbon emissions during the same period.

Additionally, from an economic perspective, shoppers care little about the expenditure on plastic shopping since it is negligible if compared with other expenditures such as telephone charges, electricity and water expenses. The reason behind this is presumably due to inexpensive plastic shopping bags have small income effect and exhibit inelastic demand. Thus, shoppers pay little attention to plastic shopping bag consumption, even though all the costs are shifted to consumers.

\section{Conclusions}

The study investigated: (1) whether ordinance of plastic shopping bags and the fee play a role in curbing bag consumption in Chinese mainland. (2) How population affect plastic bag usage as well as carbon emissions and (3) the reasons behind the failure of the plastic bags ordinance.

The empirical result is in line with our initial hypothesis that the regulation might have a short term effect, that is, along with the Beijing 2008 Olympic Games, there does appear a decrease in carbon emission in Beijing and one of the Olympic co-host cities, Tianjin. It is logical that Chinese governments, Beijing municipal government in particular, were galvanized into creating an environmentally friendly image to enhance the environmental quality for athletes from all over the world by taking advantage of this grand sport event. However, before or/and after 2008 , both the plastic shopping bags consumption and carbon emissions are on a continuous increase. Specially, the paper finds that, later on 2009, viz., after one year of the ordinance implement, carbon emissions in all 31 provinces in Chinese mainland experienced a significant carbon emissions rise. The paper thus doubts about the actual effect of the plastic bag ordinance: what if there were no Beijing 2008 Olympic Games? In hindsight, it is 
not the plastic shopping bags ordinance or/and the fee but the Beijing Olympic Games that contributes hugely to reduction of carbon emissions in 2008.

The ordinance of plastic shopping bags becomes a widely discussed topic in the literature; however, there is no size fits all for plastic bag regulation in terms of different countries. Based on the insights of existing research and as an extension of previous results, this paper sets up a simple emission function to compute the carbon emissions. Differed from Zhu (2011) and He (2010) who report a 67\% and 49\% decrease respectively in overall plastic bag use in China, our result indicates an opposite trend associated with the plastic bags ordinance in China: it is not a decrease but an increase with regard to the long term effect of carbon emissions, though we let the annual plastic bag consumption per person be 365 and 360 before and after 2008 respectively. In addition, price instrument, i.e., the fee paid on each plastic shopping bag, plays no substantial role in reducing the bag consumption. In our case, the contributing factors are population and annual bag consumption per person that induce the increase of carbon emissions. Moreover, shoppers care little about the unit bag price just as Mortimer (2017) observes that shoppers has become accustomed to the charge and returned to old habits in Ireland. Last but not least, to gain a long term decrease, concerted efforts are needed to enhance the effectiveness of the ban: a schedule is needed to phase out the free plastic bags in the near future; penalties should be imposed heavily upon those who are still manufacturing substandard bags; since fees are borne by shoppers, the revenues generated should be ring fenced in environmental fund and used to improve the environmental quality as opposed to becoming retailer's revenue (Convery et al.,2007); also, as for shoppers, they are expected to sway their behaviors to reduce plastic bag consumption which include using recyclable bags or cloth bags rather than accepting free substandard bags. It is always helpful to provide shoppers with sustainable education and outreach to reduce consumption of plastic bags at source (Xanthos et al., 2017).

Roughly speaking, there are two fundamental reasons behind the ineffectiveness of the ordinance in China. The first is, lacking effective supervision from governments at all levels, that is, after the release of the ban, China's Ministry of Commerce and various arms of governments have not paid due diligent to the actual performance of the ban, let alone take further amendments. Second, it is the producer sovereignty (the retailers are included in our case), rather than consumer sovereignty rules. Should all plastic bag producers make standard plastic bags, consumers would have no other alternatives but to buy and reuse each bag, that is, the price instrument as well as the principle of polluter (user) pays still hold. In either case, the problem would be less severe.

Finally, a limitation of this paper should be acknowledged. In particular, the conclusion may be weakened by the data plugging in the theoretical model, that is, the annual plastic bag consumption per person is 365 and 360 before and after 2008 respectively. To enhance the accuracy of estimation, an accurate number of annual plastic bag consumption per person from designed survey should be needed in future research.

\section{References}

Adriana Jakovcevic et al. (2014). Charges for plastic bags: motivational and behavioral effects. Journal of Environmental Psychology, 40, 372-380. http://dx.doi.org/10.1016/j.jenvp.2014.09.004

Alexis, R. (2017). Regulating the consumption of plastic bags in the cases of South Africa and Ireland. (Bachelor's thesis, Allegheny College, Meadville, USA). Retrieved from https://dspace.alegheny.edu

Arı, E., \& Yılmaz, V. (2017). Consumer attitudes on the use of plastic and cloth bags. Environment, Development and Sustainability, 19, 1219. https://doi.org/10.1007/s10668-016-9791-x

Clapp, J., \& Swanston, L. (2009). Doing away with plastic shopping bags: international patterns of norm emergence and policy implementation. Environmental Politics, 18, 315-332.

Convery, F., Mc Donnell, S., Ferreira, \& Susana. (2007). The most popular tax in Europe? Lessons from the Irish plastic bags levy. Environmental and Resource Economics, 38, 1-11.

Hasson, R., Leiman, A., \& Visser, M. (2007). The economics of plastic bag legislation in South Africa. South African Journal of Economics, 75, 1.

He, H. R. (2010). The effects of an environmental policy on consumers: lessons from the Chinese plastic ban regulation. Working paper in Economics No.453. University of Gothenburg, Göteborg, Sweden.

Martinho, G., Balaia, N., \& Pires, A. (2017). The Portuguese plastic carrier bag tax: the effects on consumers' behavior. Waste Management, 61, 3-12. https://doi.org/10.1016/j.wasman.2017.01.023

McLaughlin, K. (2004). Wrap that in plastic? Not in Taiwan, unless you pay. Retrieved from http://www.csmonitor.com/2004/0615/p07s02-woap.html 
Mortimer, G. (2017). Getting rid of plastic bags: A windfall for supermarkets but it won't do much for the environment. The Conversation, July(17). Retrieved from https://eprints.qut.edu.au/110843/

Rivers, N., Shenstone-Harris, S., \& Young, N. (2017). Using nudges to reduce waste? The case of Toronto's plastic bag levy. Journal of Environmental Management, 188, 153-162. https://doi.org/10.1016/j.jenvman.2016.12.009.

Saidan, M. N., Ansour, L. M., \& Saidan, H. (2017). Management of plastic bags waste: an assessment of scenarios in Jordan. Journal of Chemical Technology and Metallurgy, 52, 148-154.

Wagner, T. P. (2017). Reducing single-use plastic shopping bags in the USA. Waste Management. https://doi.org/10.1016/j.wasman.2017.09.003

Wang, S. H., \& Song, M. L. (2014) Review of hidden carbon emissions, trade, and labor income share in China, 2001-2011. Energy Policy, 74, 395-405.

Wang, S. H., Song, M. L. \& Yu, T. (2016). Hidden carbon emissions, industrial clusters, and structure optimization in China. Computational Economics. https://doi.org/10.1007/s10614-016-9570-7

Xanthos, D., \& Walker, T. R. (2017). International policies to reduce plastic marine pollution from single-use plastics (plastic bags and microbeads): A review. Marine Pollution Bulletin, 118, 17-26.

Zhu, Q. F. (2011). An appraisal and analysis of the law of "Plastic-Bag Ban". Energy Procedia, 5, 2516-2521.

\section{Copyrights}

Copyright for this article is retained by the author(s), with first publication rights granted to the journal.

This is an open-access article distributed under the terms and conditions of the Creative Commons Attribution license (http://creativecommons.org/licenses/by/4.0/). 